\title{
Isolation of endophytics fungi from Cola acuminata Schott \& Endl, and antifungal activity against Candida $S p$
}

\author{
Mfouapon Mbetyoumoun Heroine, Hzounda Fokou Jean Baptiste, Yimgang Victorine Lorette,Toghueo \\ Kouipou Rufin Marie, Fogue Soubgwi Pythagore, Eke Pierre, Fekam Boyom Fabrice, Kuiate Jules- \\ Roger
}

\section{ABSTRACT}

The discovery of novel antifungal agents with low toxicity and high therapeutic efficacy is needed to overcome the limitation of the actually existing antifungal therapies. Endophytic fungi acknowledge for their outstanding ability to produce bioactive metabolites can be exploited for this purpose. Therefore, this study was designed to investigate the antifungal potential of endophytic fungi leaving in tissues of Cola acuminata. Endophytic fungi associated with Cola acuminata were isolated from healthy and matured plant tissues and characterized based on their morphological and microscopic characters. Each isolated fungus was cultured on potato dextrose broth for ten days and crude extract prepared from the resulting medium after filtration. The resulting extracts were tested for their antifungal potential using broth microdilution method. One hundred and six fungal isolates were obtained from leaves, fruit, stem, stem bark, root, and root bark of $C$. acuminate. They belong to six genera including Aspergillus, Alternaria, Curvularia, Cunnighamella, Fusarium, Trichoderma. Non-sporulating isolates were designated as Mycelia. Out of the 106 extracts screened for their antifungal activities, 21, 13 and 43 showed antifungal activities against C.albicans NR-29450, C.parapsilosis ATCC 22019 and C.krusei ATCC 6258 respectively. Five of these isolates including $C a 114, C a s b 122, C a b 259, C a b 31$ and $C a b 244$ were the most potent, inhibiting the growth of the three tested Candida species more than $85 \%$ against. Isolate Casb122 appears to be one of the most potent antifungal against Candida species (MIC $500-1000 \mu \mathrm{g} / \mathrm{mL}$ ). The results suggest that endophytic fungi from $C$. acuminata can produce metabolites with antifungal activity.

Keywords: Cola acuminata, endophytic, fungi, antifungal, Fusarium oxysporum.
Published Online: September 5, 2020

ISSN: $2684-5199$

DOI : 10.24018 /ejbio.2020.1.5.72

Mfouapon Mbetyoumoun Heroine

Research Unit of Microbiology and Antimicrobial Substances, University of Dschang, Cameroon.

(e-mail: amshermfouapon@yahoo.fr)

Hzounda Fokou Jean Baptiste

Antimicrobial Agents Unit, Laboratory for Phytobiochemistry and Medicinal Plants Studies, University of Yaoundé 1, Cameroon.

(e-mail: hzoudafokou@yahoo.fr)

Yimgang Victorine Lorette

Antimicrobial Agents Unit, Laboratory for

Phytobiochemistry and Medicinal Plants Studies, University of Yaoundé 1, Cameroon.

(e-mail: vyimgang@yahoo.fr)

Toghueo Kouipou Rufin Marie

Antimicrobial Agents Unit, Laboratory for Phytobiochemistry and Medicinal Plants Studies, University of Yaoundé 1, Cameroon.

(e-mail: togheuorufin ${ }^{\circledR}$ yahoo.fr) Fogue Soubgwi Pythagore

Research Unit of Microbiology and Antimicrobial Substances, University of Dschang, Cameroon.

(e-mail: pythagorefogue@yahoo.fr)

Eke Pierre

Antimicrobial Agents Unit, Laboratory for Phytobiochemistry and Medicinal Plants Studies, University of Yaoundé 1, Cameroon.

(e-mail: ekepierre@yahoo.com)

Fekam Boyom Fabrice

Antimicrobial Agents Unit, Laboratory for Phytobiochemistry and Medicinal Plants Studies, University of Yaoundé 1, Cameroon.

(e-mail: ffefe@yahoo.com)

Kuiate Jules-Roger*

Research Unit of Microbiology and Antimicrobial Substances, University of Dschang, Cameroon.

(e-mail: jrkuiate@yahoo.com)

*Corresponding Author 


\section{INTRODUCTION}

Mycoses still one of the major health issues in the world [1]. Due to the continue increase in number of immunocompromised patients and other factors such as the use of broad spectrum antibiotics aggressive anticancer chemotherapy and organ transplantation, the incidence of candidiasis have drastically increase over the past decades [2]. Antifungal agents available for the treatment of systemic or mucosal candidiasis are restricted to only a few classes of compounds with limited efficacy. For decades, the treatment has relied on fungicidal polyenes drugs such as amphotericin $\mathrm{B}$, which binds to the fungal ergosterol and recently, fungistatic drugs such as the azoles (fluconazole) have become more widely used to treat fungal infection due to the comparative ease of their use [3]. However, adverse side effects, toxicity, and emergence of drug resistance limit the use of these drugs [4]. More distressing situation is the fact that various Candida species can acquire resistance to different antifungals or, even worse, to more than one drug [5]. Indeed, multidrug-resistant Candida spp. have been reported all over the world over the past decade [6] and recently with the discovery of a new worrisome and globally emerging life threatening and multidrug resistant Candida auris, posing a further threat to our ability to use antifungal drugs to treat candidiasis [7]. Therefore, new compounds that could constitute starting points for new drug antifungal discovery are clearly needed. The investigation of natural products for new lead discovery has proven to be a successful approach for centuries. Indeed, estimates suggests that more than $70 \%$ antimicrobial drug in clinical use are natural product or natural product derivatives [8]. In fact, natural products are adapted to a specific function in nature and constitute therefore an excellent source for novel secondary metabolites. The search for new agents should concentrate on organisms such as endophytic fungi inhabiting novel biotopes in nature [9]. Endophytes defined as "microbes that colonize living, internal tissues of plants without causing any immediate, overt negative effects" [10], are found in virtually every plant on earth. These organisms reside in the living tissues of the host plant and do so in a variety of relationships ranging from symbiotic to pathogenic. In culture, outside of their host tissue, endophytic fungi are also known to produce a number of important secondary metabolites including anticancer, anti-fungal, anti-bacterial anti-diabetic and immunosuppressant compounds [11], [12]. Therefore, investigating this group of microorganisms can lead to the discovery of new antifungal agents. The current study was conducted to isolate, characterize and screen endophytic fungi from $C$. acuminata growing in Cameroon for their antifungal activity.

\section{MATERIALS AND METHODS}

\section{A. Materials}

\section{Microorganisms}

Fungal strains used to test endophytes antifungal activities included Candida albicans NR-29451 from Biodefense and Emerging Infections (BEI resources), Candida parapsilosis ATCC 22019 and Candida krusei ATCC 6258 from the American Type Culture. These microorganisms were maintained on agar slope at $4^{\circ} \mathrm{C}$ and sub-cultured for $48 \mathrm{~h}$ before use.

\section{Plant material}

Mature and healthy Cola acuminata were collected in west-Cameroon and stored in sterile plastic bags and transported to the laboratory within 48hours for isolation of endophytic fungi. The identification of plant species was done at the Cameroon National Herbarium by comparison to Voucher specimens under the identification number 5368/SRFK.

\section{B. Methods}

\section{Isolation and identification of endophytic fungi from} Cola acuminata

a) Isolation

For each plant tissue and organs (leaves, fruit, stem, stem bark, root or root bark), fragments of about $5 \mathrm{~mm}$ were thoroughly washed separately in running tap water, then surface sterilized by submerging them in $70 \%$ ethanol for 5 minutes, followed by $1 \%$ sodium hypochlorite $(\mathrm{NaOCl})$ solution for $15 \mathrm{~min}, 70 \%$ ethanol for $2 \mathrm{~min}$ and rinse with sterile distilled water. The resulting disinfected samples were plated (20 pieces/organ/plate) onto potato dextrose agar (PDA; pH 5.6) supplemented with chloramphenicol (200 $\mathrm{mg} / \mathrm{L})$ and kept in dark at room temperature $\left(25 \pm 2{ }^{\circ} \mathrm{C}\right)$. Five plates were prepared per sample. Mycelial tips emerging from plant fragments were transferred onto fresh PDA free of chloramphenicol to obtain pure cultures (Fig. 2). Continuous maintenance of endophytes was achieved by regular transfer on PDA slants under aseptic conditions to keep the culture freehand viable. Each colonization frequency of each isolated and identified endophyte was calculated using the following formula [13]:

Colonisation frequency

$=\frac{\text { Number of fragments colonized by the endophytic fungi }}{\text { Number of fragments deposit on the culture medium }} \times 100$

\section{b) Identification of fungi isolates}

The isolated endophytes were identify based on the morpho-cultural characteristics. For this purpose, they were cultured on PDA plates at $28{ }^{\circ} \mathrm{C}$ for 7 days. For identification macroscopic characteristics of colonies including shape, size, color, and surface texture, observed daily were used. These macroscopic characters were associated to microscopic features like the size and shape of hyphae, conidia and conidiophores of isolates grown on PDA plates for 7 days [14]-[17]. These identifications were limited at the genus level.

\section{Screening of endophytes antifungal activities}

a) Fermentation and preparation of endophytes extracts

The isolated endophytic fungi were cultured at $28{ }^{\circ} \mathrm{C}$ in a $250 \mathrm{~mL}$ round bottom flask containing $20 \mathrm{ml}$ of potato dextrose broth (PDB) medium for 3 incubation periods: 5, 10 and 15 days. The culture was shacked (with an electronic shaker IKA-VIBRAX-VXR) at $150 \mathrm{rpm}$ all over the incubation periods. At the end of each incubation time, culture media was separated from mycelium by centrifugation at $4500 \mathrm{rpm}$ for $20 \mathrm{~min}$ at $4{ }^{\circ} \mathrm{C}$. The resulting culture media was extracted thrice, using $20 \mathrm{~mL}$ of ethyl acetate. This mixture was then transferred to a separator funnel that permitted to separate the organic phase from aqueous phase. The crude extract was obtained after evaporation of the upper phase at $40{ }^{\circ} \mathrm{C}$ in a rotary 
evaporation system (BÜCHI 461). The obtained residue was subjected to evaporation to dryness to afford the crude ethyl acetate extract.

\section{b) Antifungal screening of endophytes crude extracts}

Preparation of stock solution and reference drug

The stock solution of crude extract was prepared at $160 \mathrm{mg} / \mathrm{mL}$ using DMSO $20 \%$ in water. Indeed, $160 \mathrm{mg}$ of extract were introduced in $100 \mu \mathrm{L}$ of $20 \%$ DMSO and the final volume completed to $1 \mathrm{~mL}$ with sterile distilled water. The stock solutions were filter-sterilized with a $0.2 \mu \mathrm{m}$ syringe and stored at $4^{\circ} \mathrm{C}$.Fluconazole (Sigma Aldrich) was used as reference drug and prepared at $2 \mathrm{mg} / \mathrm{mL}$ in DMSO $20 \%$.

\section{Antifungal activity}

Each endophytic extract was tested for its antifungal activities using broth dilution method in 96-wells microtitre plates as described by the Clinical Laboratory Standards Institute M27-A3 [18]. In the first ligne of the 96-wells plate, $190 \mu 1$ of Sabouraud dextrose Broth were introduced and $10 \mu \mathrm{L}$ of stock extract solution added. From these wells, 100 $\mu \mathrm{L}$ of the solution were pipetted and introduced in the next well containing $100 \mu \mathrm{L}$ of SDA and so on and so for. Extract solution $(100 \mu \mathrm{L})$ and reference drugs (fluconazole) in Sabouraud dextrose broth (Hi Media) were added to the wells, followed by addition of $100 \mu \mathrm{L}$ of candida inoculum standardized at $2.50 \times 10^{3}$ cells $/ \mathrm{mL}$ to reach $4 \mathrm{mg} / \mathrm{mL}$ concentration for each extract. A blank column was included for sterility control. After 48 hours of incubation at $37{ }^{\circ} \mathrm{C}$, absorbance of each plate was measured using a Magellan Infinite M200 multi-well plate reader (Tecan) $490 \mathrm{~nm}$. The percentage inhibition was calculated as compared to negative control. Only extract with percentage inhibition higher than $80 \%$ was considered as active.

$$
\begin{gathered}
\text { Percentage of inhibition }= \\
=\frac{\text { Absorbance of test well }}{\text { absorbance of the negativ control well }} \times 100
\end{gathered}
$$

The minimum inhibitory concentration (MIC) of selected extracts against yeasts was determined as previously described [20] using 96-wells microtiter plates. The concentrations of extracts tested ranged from 125, 250, 500, 1000,2000 , and $4000 \mu \mathrm{g} / \mathrm{mL}$. For a fluconazole, concentration was ranged from $4 \mu \mathrm{g} / \mathrm{mL}$ to $128 \mu \mathrm{g} / \mathrm{mL}$ according to the preliminary test on agar medium. After 48 hours of incubation at $37^{\circ} \mathrm{C}$, the turbidity was observed as an indication of growth. MIC was defined as the lowest concentration inhibiting the visible growth of yeasts.

\section{RESULTS}

\section{A. Identities of isolated endophytic fungi from C. acuminata}

One hundred and six (106) endophytic fungal isolates were obtained from 600 tissue segments of $C$. acuminate, including leaves, fruit, stem, stem bark, root, and root bark. Based on their morphocultural and microscopic features, they were identified as belong to six different genera: Aspergillus, Alternaria, Curvularia, Cunnighamella, Fusarium and Trichoderma. Fifty-six of these isolates were imperfect nonsporulating fungi and were categorized as Mycelia sterilia.

\footnotetext{
1. Trichoderma spp.
}

Trichoderma colonies showed variable aspects, sometimes slightly flaky and other times compacted in clumps. Between these two extremes, intermediate aspects have been observed. The conidium gives rise to a sterile, white, sterile first mycelium, and then takes on a visible green color on the aerial parts of the mycelium, corresponding to conidiogenesis (Fig. $1 \mathrm{a}$ and 1b). Under microscope, the mycelium appears composed of yellow, septate, branched, smooth-walled hyphae (Fig. 1c). Conidiophores have a conical or pyramidal shape. Very branched, they wear phialides in the form of flanges or bowling pins. In turn, phialides carry spores (Fig. 1d).

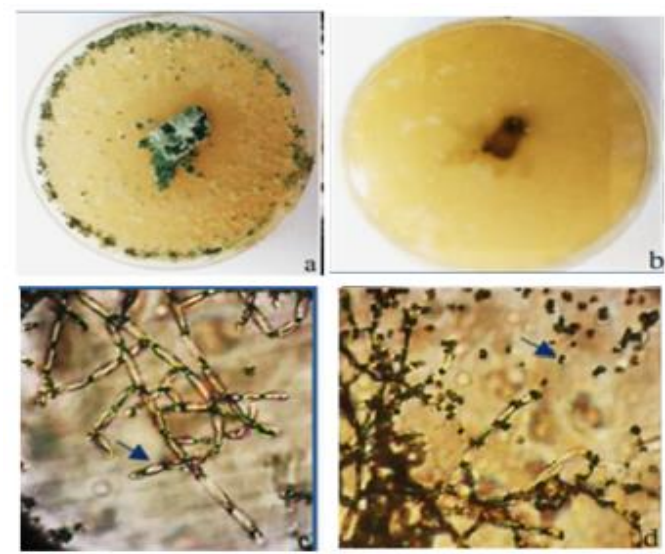

Fig. 1. Morphological characteristics of Trichoderma sp on Potatoes Dextrose Agar Medium. General mycelial aspect and color (both sides), c. phyphae d. Microconidia.

\section{Fusarium Spp.}

Colonies of Fusarium were characterized by a rapid growth on PDA medium. Colonies were flat, whitish to yellowish in color (Fig. 2a). These colors either remained with time or changed into purple or whitish on the reverse of the culture (Fig. 2b). Macroconidia present several lodges, with a little or no curved shape, form of the basal cell (Fig 2c). The microconidia are dispersed among the mycelium, small in size compared to macroconidia and more often consist of one or two cells fusiform, pear-shaped, ellipsoid, ovoid or subglobose (Fig. 2d). Chlamydospores when they exist are terminal, or intercalated, isolated or in groups or chains (Fig. 2d)

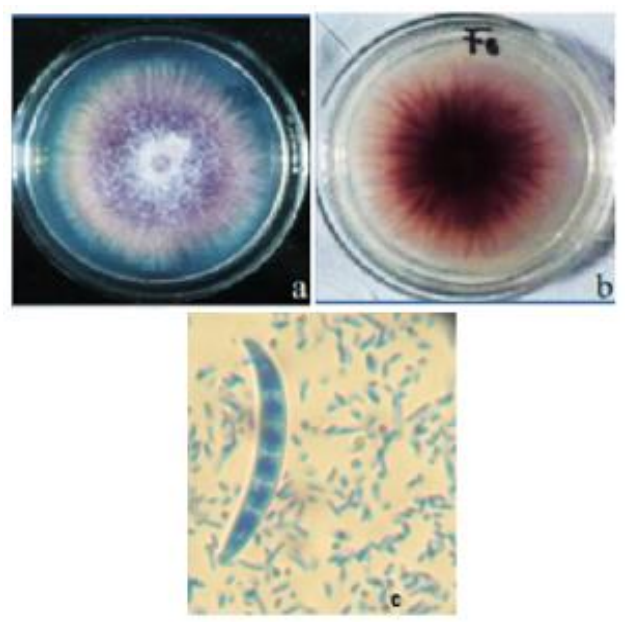

Fig. 2. Morphological characteristics of Fusarium sp on Potatoes Dextrose Agar Medium. General mycelial aspect and color (both sides), c. macro and microconidia. 


\section{Aspergillus Spp.}

Cultured on PDA medium, Aspergillus colonies showed variable aspects on the front: white then green, green-gray then dark green, fluffy to powdery, white then yellow to yellow-green, white then yellow then granular and blackish (Fig. 3a).The reverse of these colonies were colorless, yellow, green, red-brown, or pale yellow (Fig. 3b). Microscopic features include hyphae that develops into vegetative and reproductive hyphae with conical heads with large and black globes (Fig. 3c).

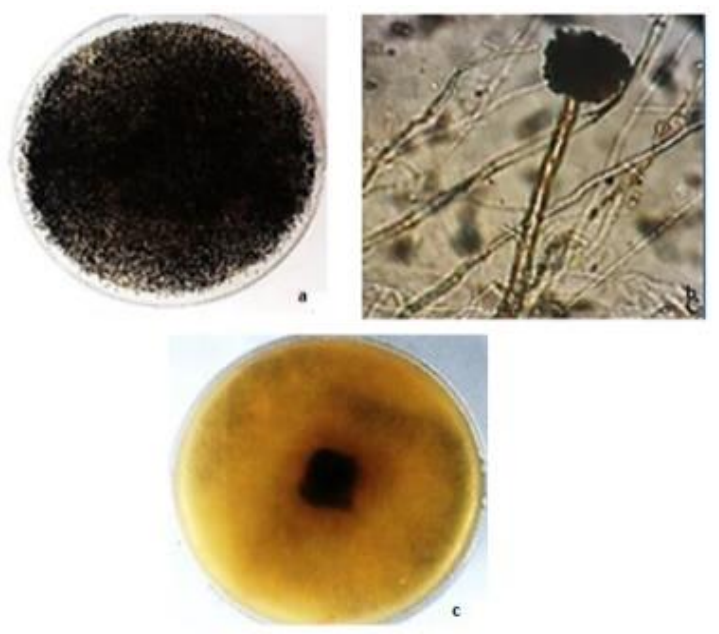

Fig. 3. Morphological characteristics of Aspergillus sp on Potatoes Dextrose Agar Medium. General mycelial aspect and color (both sides), c. conidiophore.

\section{Alternaria Spp.}

Cultured on PDA medium, Alternaria is fast-growing, with black or gray or greenish-gray and woolly colonies (Fig. 4a). The reverse of the culture is black (Fig. 4b). Conidiophores are erect and swollen at their ends in spherical or ovoid heads (Fig. 4c). The conidia are wall-shaped, isolated or grouped from the conidiophore. They are brown, pear-shaped or ovoid, with an enlarged base with transverse, longitudinal, oblique, variable number of septations.
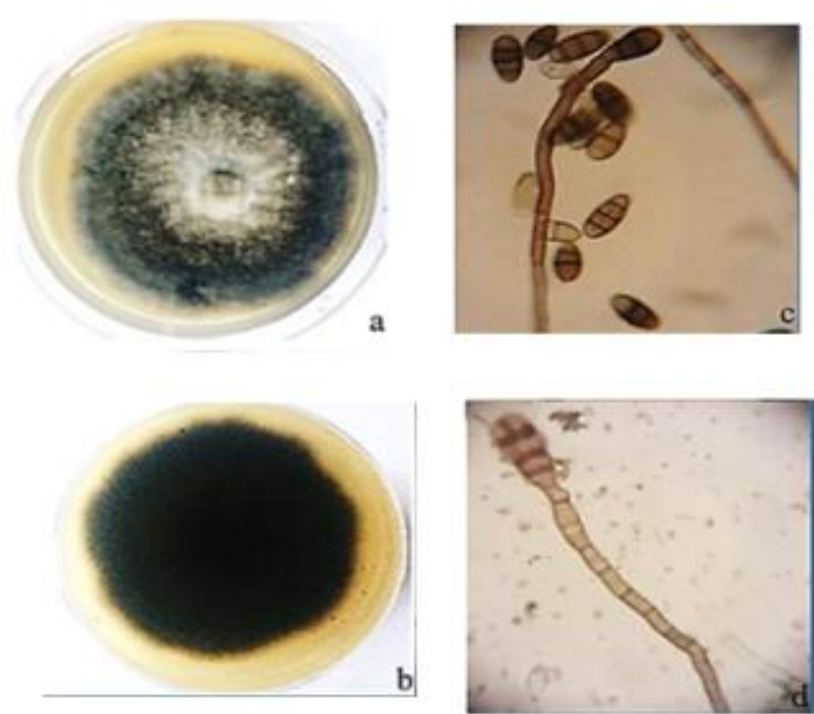

Fig. 4. Morphological characteristics of Alternaria sp on Potatoes Dextrose Agar Medium General mycelial aspect and color (both sides), c. macroconidia d: conidiophore.

\section{Curvularia Spp.}

Grown on PDA, it produced effuse colonies with grey cottony mycelia becoming blackish - brown when forming conidia and conidiophores (Fig. 5a).The reverse of the culture is black (Fig. 5b).The observed conidiophores were smoothwalled mononematous and macronematous. Conidia were solitary, often curved, rounded at the end with mostly 3 rarely 4- 5 transverse septates with dark bands (Fig. 5c).
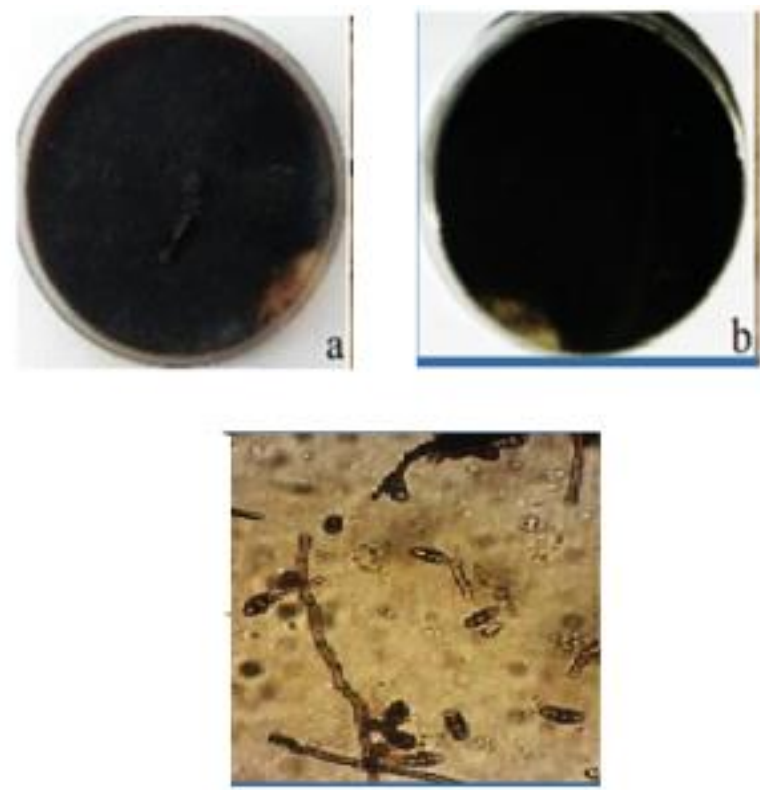

Fig. 5. Morphological characteristics of Curvularia spp on Potatoes Dextrose Agar Medium. General mycelial aspect and color (both sides), c. maroconidia.

\section{Cunninghamella Spp.}

The colonies on PDA are fast growing and extensive, flaky, white in color becoming gray (Fig. 6a). The reverse is colorless to yellowish (Fig. 6b). The mycelia are broad, irregular and not septate. The sporocystophores are simple or branched with the dilated end into a spherical to oval vesicle, of variable size. On these vesicles are formed external sporangioles containing a spore (Fig. 6c).
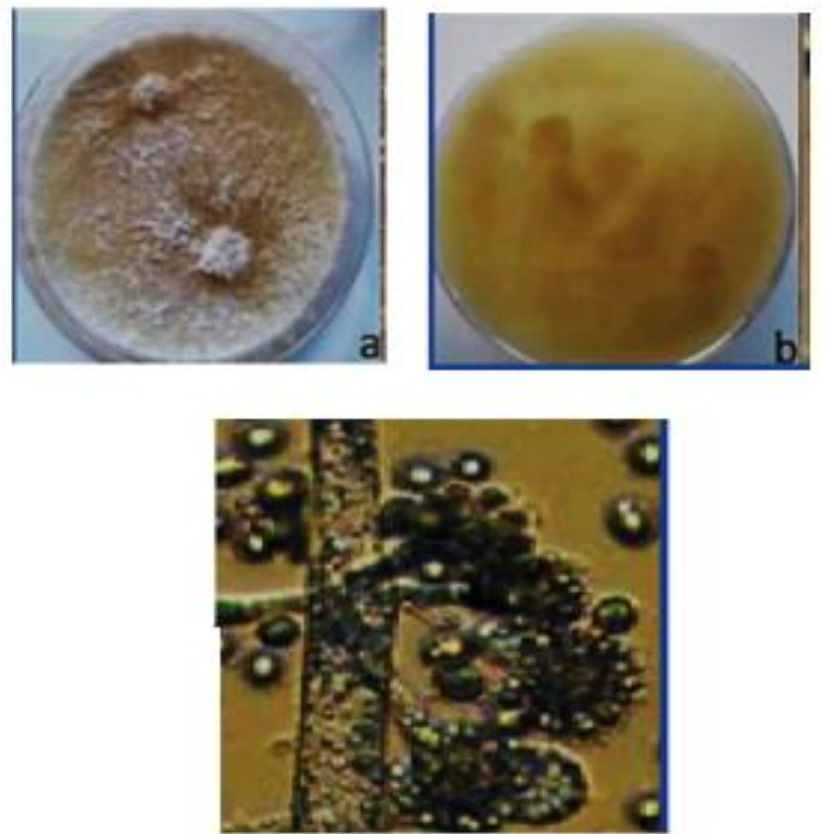

Fig. 6. Morphological characteristics of Cunninghamella Spp on Potatoes Dextrose Agar Medium. General mycelial aspect and color (both sides), c. conidiophore. 


\section{B. Distribution of endophytes isolates in different tissues and organs of $C$. acuminate}

The isolated endophytes were unequally, both in qualitative and quantitative point of view, distributed in the various screened organs of $C$. acuminata. Alternaria spp, Cunnighamella spp and Trichoderma spp were isolated only in stem. Fusaruim was found in stem bark and leaves while Aspergillus, the most predominant genera in C. acuminata was present in almost all the organs except in fruits (Table 1). Cola acuminata stem and root were dominantly infected by Aspergillus spp followed by Mycelia sterilia, whereas stem bark, root bark and leaves were dominated by Mycelia sterilia followed by Aspergillus spp.

\section{Quantities of endophytes extracts and their antifungal properties}

The evolution extraction yields of culture media with ethyl acetate varied according to endophyte isolates. Then the production of secondary metabolites by endophytes in culture varied according to isolates. Thus, with isolate cab244, the extraction yield increases from days 5 to day 15, while with isolates Cab14 and Cab31j, yield remain constant between day 5 and 10, and then increased between day 10 and 15. A reverse situation was observed with Casb122. With Cab259, the extraction yield increase between day 5 and 10, then remain constant between day 10 and 15 (Fig. 7).

TABLE 1: FREQUENCY OF ENDOPHYTES FUNGI ISOLATED PER ORGANS OF COLA ACUMINATA

\begin{tabular}{|c|c|c|c|c|c|c|c|}
\hline Fungi genera & Stem & Stembark & Rootbark & Leaves & Fruit & Root & Total number of isolates \\
\hline Mycelia sterilia & 11 & 9 & 15 & 11 & 4 & 6 & 56 \\
\hline Alternaria & 2 & & - & - & - & - & 2 \\
\hline Aspergillus & 12 & 5 & 2 & 6 & - & 12 & 37 \\
\hline Curvularia & - & - & 1 & 1 & - & 1 & 3 \\
\hline Fusarium & - & 1 & - & 1 & - & - & 2 \\
\hline Cunnighamella & 1 & - & - & - & - & - & 1 \\
\hline Trichoderma & 4 & - & - & - & - & - & 4 \\
\hline Total number of isolates & 30 & 15 & 18 & 19 & 4 & 20 & 106 \\
\hline Infection frequency (\%) & 30 & 15 & 18 & 19 & 4 & 20 & - \\
\hline
\end{tabular}

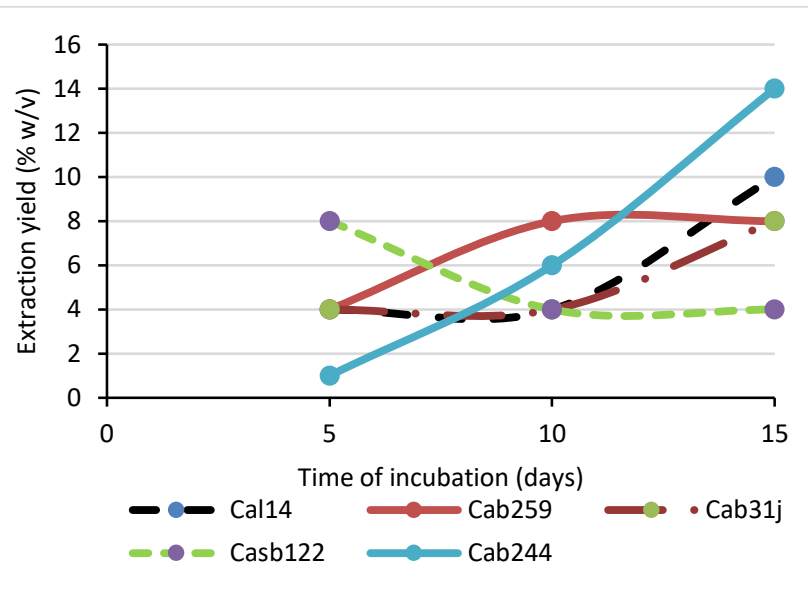

Fig. 7. Variation of extraction yield of endophyte cultures as a function of incubation time.

Extracts of endophyte isolates that were prepared exhibited different antifungal activities vis-a-vis of the three Candida strains tested and depending on the organ where they were isolated (Table 2). The isolates obtained from fruits and roots were practically not active on the tested Candida species tested. On the other hand, stembark and rootbark gave more active isolates than stem. C. krusei was susceptible to 43 extracts while $C$. albicans and $C$. parapsilosis were sensitive to 21 and 13 endophytes extracts respectively. The number of active endophytes from root and fruits on the three candida species was very low. However, based on the percent inhibition of the extracts from endophytes cultures, and having set the bar at $80 \%$, only five isolates were actually active (Table 3). Concerning MIC, only extract of isolate Casb122 identified as Fusarium spp was appears to be one of the most potent antifungal against Candida species (Table 4).

TABLE 2: DISTRIBUTION OF ACTIVE ISOLATES IN DIFFERENT ORGANS OF COLA ACUMINATA

\begin{tabular}{lccc}
\multicolumn{4}{c}{ COLA ACUMINATA } \\
\hline \multicolumn{3}{c}{ Human pathogenic fungal strains } \\
\hline \multicolumn{1}{c}{ Plant } & C. albicans NR- & C. parapsilosis & C. krusei ATCC \\
organs & $\mathbf{2 9 4 5 0}$ & ATCC 22019 & $\mathbf{6 2 5 8}$ \\
\hline Stem & $3 / 30(10.0 \%)$ & $6 / 30(20.0 \%)$ & $9 / 30(30.0 \%)$ \\
Stembark & $9 / 15(60.0 \%)$ & $2 / 15(13.33 \%)$ & $10 / 15(66.66 \%)$ \\
Rootbark & $4 / 18(22.22 \%)$ & $2 / 18(11.11 \%)$ & $9 / 18(50.0 \%)$ \\
Leaves & $5 / 19(26.31 \%)$ & $3 / 19(15.78 \%)$ & $13 / 19(68.42 \%)$ \\
Fruits & $0 / 4(0.0 \%)$ & $0 / 4(0.0 \%)$ & $1 / 4(25.0 \%)$ \\
Roots & $0 / 20(0.0 \%)$ & $0 / 20(0.0 \%)$ & $1 / 20(5.0 \%)$ \\
Total & $21 / 106(19.81 \%)$ & $13 / 106(12.26 \%)$ & $43 / 106(40.56 \%)$ \\
\hline & & &
\end{tabular}

TABLE 3: THE MOST ACTIVE ISOLATES AGAINST THE THREE CANDIDA SPP

\begin{tabular}{lccc}
\hline \multicolumn{4}{c}{ Candida species } \\
\hline Endophitic fungi & $\begin{array}{c}\boldsymbol{C} \text {. } \\
\text { albicans }\end{array}$ & $\begin{array}{c}\text { parapsilosis } \\
\text { Cal14 }\end{array}$ & $\boldsymbol{C}$. krusei \\
Casb122 & $99,27 \%$ & $86,55 \%$ & $80,96 \%$ \\
Cab259 & $90,41 \%$ & $98,59 \%$ & $81,83 \%$ \\
Cab31j & $86,73 \%$ & $90,35 \%$ & $87,29 \%$ \\
Cab244 & $87,73 \%$ & $88,38 \%$ & $88,66 \%$ \\
\hline
\end{tabular}

TABLE 4: MIC OF ENDOPHYTE EXTRACT AGAINST SEVEN C. ALBICANS ISOLATES (X102 $\mu \mathrm{G} / \mathrm{ML})$

\begin{tabular}{lcccccccc}
\hline & \multicolumn{8}{c}{ Human pathogenic C. albicans (C.a) isolates } \\
\cline { 2 - 9 } $\begin{array}{l}\text { Endophytes } \\
\text { extract }\end{array}$ & C.a & C.a & C.a & C.a & C.a & C.a & C.a & C.a \\
\hline Caf14 & 20 & 20 & 20 & 20 & 20 & 20 & 20 & 20 \\
Is2 & Is3 & Is4 & Is5 & Is6 & Is7 & NR29451 \\
Cat31j\$ & 20 & 20 & 20 & 20 & 20 & 20 & 20 & 20 \\
Cat259 & 20 & 20 & 20 & 20 & 20 & 20 & 20 & 20 \\
\hline aEt122 & 10 & 10 & 5 & 10 & 10 & 10 & 10 & 10 \\
\hline
\end{tabular}




\begin{tabular}{lcccccccc}
\hline Cat244 & 20 & 20 & 20 & 20 & 20 & 20 & 20 & 20 \\
Fluconazole & 1.28 & 0.64 & 0.3 & 1.28 & 1.28 & 1.28 & 0.64 & 1.28 \\
\hline
\end{tabular}

\section{DISCUSSION}

The role of endophytes in plants is comparable to that of the intestinal microbiota in animals. Several endophytes have properties that potentiate the growth of host plants or its resilience to certain stress factors [19], [20]. In this study, one hundred and six (106) endophytic fungal isolates were obtained from different organs of $C$. acuminata. These results demonstrate that all the organs investigated are host of one or more endophytic fungi as previously described [21]-[23]. In some cases, endophytes appear to be non-pathogenic and then benefit to host plant in a symbiotic association. But in some cases, in plant-endophyte interactions, endophytic fungi can potentially become pathogens or saprotrophs [24], [25].

These endophytic fungi were classified by morphological analysis into six (6) genera including Aspergillus, Alternaria, Curvularia, Cunnighamella, Fusarium, Trichoderma and Mycelia sterilia for the non sporulating fungi. All the genera found in the present study have been also reported in several other studies [26], [27]. The most dominant genus found in all C.acuminata's parts was Aspergillus spp. which is the common endophytic fungi from several tropical plants investigated till date.

The 106 endophytic fungi isolated were cultured in liquid potatoes medium and afforded extracts were tested against Candida spp. Out of the extracts tested, 21, 13 and 43 extracts were active against C.albicansNR-29450 and C.krusei ATCC 6258.The results show that a great percentage of fungi are producing active metabolites against candida spp. These results are in accordance with previous studies with reported that a high proportion of endophytic fungi $(80 \%)$ produce biologically active compounds in tests for antibacterial, fungicidal and herbicidal activities [28], [29]. Endophytic fungi are therefore an alternative source for the production of new antifungal agents [30], [31]. Among the active isolates, five including Cal14, Casb122, Cab259, Cab31 and Cab244 were the more potent with percentage inhibition of more than $80 \%$. The most potent extract against all the tested microorganisms with MIC values ranged from 500-1000 $\mu \mathrm{g} / \mathrm{mL}$ was from isolate Casb122. This may suggest that this isolate can produce potent antifungal compounds. Indeed, previous studies reported the antifungal metabolites produced by some endophytic fungi species from medicinal plants.

In fact, ambuic acid, a highly functionalized antifungal compound was isolated from both endophytic fungi Pestalotiopsis sp and Monochaetia sp by [32]. Another compound named Fusidikactones with good antifungal activity was produced by endophytic Fusidium species [33]. In addition, the endophytic fungus Cryptosporiopsis quercina was found to produce Cryptocandin and Cryptocin. In fact, Cryptocandin and its related compounds named, echinocandins and pneumocandins demonstrated excellent antifungal activity against Candida albicans and Trichophyton spp, Sclerotinia sclerotiorum and Botrytis cinerea and are currently being used against a number of fungi causing diseases of the skin and nails [11], [34].

\section{CONCLUSION}

The present investigation gives an insight into the fungal endophytes associated with the Cameroonian medicinal plants, Cola acuminata and their antifungal potential. The results demonstrate that endophytes isolated have the potential to provide novel pharmacophores against the Candida spp. This also supports the fact that screening of endophytes from medicinal plants can lead to the identification of potent compounds. Further studies are ongoing to optimize the condition for antifungal production by the most potent fungus F.oxysporum.

\section{ACKNOWLEDGMENT}

The authors are grateful to the National Herbarium of Cameroon for identification of Cola acuminalta.

\section{REFERENCES}

[1] Bongomin F, Gago S, Oladele RO, Denning DW. Global and MultiNational Prevalence of Fungal Diseases-Estimate Precision. J. Fungi. 3(4):57, 2017. https://doi.org/10.3390/jof3040057.

[2] Mohandas V, Ballal M. Distribution of Candida Species in Different Clinical Samples and their Virulence: Biofilm Formation, Proteinase and Phospholipase Production: A Study on Hospitalized Patients in Southern India. J Glob Infect Dis. 3: 4-8, 2011.

[3] Oliver BG, Silver PM, Marie C, Hoot SJ, Leyde SE, White TC. Tetracycline alters drug susceptibility in Candida albicans and other pathogenic fungi. Microbiology. 154: 960-970, 2008

[4] Brown GD, Denning DW, Gow NA, Levitz SM, Netea MG, White TC. Hidden killers: human fungal infections. Sci Transl Med. 4:165rv113, 2012. https://doi:10.1126/scitranslmed.3004404.

[5] Reales-Calderon JA, Molero G, Gil C, Martinez JL. The fungal resistome: a risk and an opportunity for the development of novel antifungal therapies. Future Med Chem. 8:1503-1520, 2016 https://doi:10.4155/fmc-2016-0051

[6] Fadda ME, Podda GS, Pisano MB, Deplano M, Cosentino S. Prevalence of Candida species in different hospital wards and their susceptibility to antifungal agents: results of a three year survey. J Prev Med Hyg, 49:69-74, 2008.

[7] Navalkele BD, Revankar S, Chandrasekar P. Candida auris: a worrisome, globally emerging pathogen. Expert. Rev. Anti Infect Ther. 15:819-827, 2017. https://doi:10.1080/14787210.2017.1364992.

[8] Mc Alpine JB, Bachmann BO, Piraee M, Tremblay S, Alarco AM, Zazopoulos E, et al. Microbial genomics as a guide to drug discovery, structural elucidation: ECO02301, a novel antifungal agent, as an example. J Nat Prod. 2005; 68:493-496.

[9] Schulz B, Boyle C, Draeger S. Endophytic fungi: a source of biologically active secondary metabolites. Cambridge University $\begin{array}{lll}\text { Press. } & 106: 996-1004, & 2002 .\end{array}$ DOI: https://doi.org/10.1017/S0953756202006342.

[10] Stone JK, Bacon CW, White JFJr. An overview of endophytic microbes: endophytism defined. In: Microbial Endophytes (eds. C.W. Bacon and J.F. White, Jr.). Marcel Dekker, Inc.: New York: 3-29, 2000

[11] Strobel G, Daisy B. "Bioprospecting for microbial endophytes and their natural products". Microbiol Mol Biol R. 67:491-502, 2003.

[12] Toghueo KRM, Boyom FF. Endophytic Fungi from Terminalia Species: A Comprehensive Review J Fungi. 5:43, 2019. https://doi:10.3390/jof5020043.

[13] Sunayana N, Prakash HS. Fungal endophytes of Boswellia Serrata Roxb. (Burseraceae), a medicinal tree species. Int J Pharm Biol Sci. $1: 1-5,2012$.

[14] Kubicek CP, Harman GE. Trichoderma and Gliocladium Basic Biology, Taxonomy and Genetics. Vienne, Geneva, New York. 14-24, 2002.

[15] Leslie JF, Summerell BA. The Fusarium Laboratory Manual, $1^{\text {st }}$ ed; Blackwell Publishing Professional, USA, 101-117, 2006.

[16] Domsch KH, Gams W, Anderson TH. Compendium of soil fungi. $2^{\text {nd }}$ ed. IHW-Verlag, Eching, Germany. 672, 2007. 
[17] Sandhu SS, Kumar S, Aharwal RP. Isolation and Identification of endophytic fungi from Ricinus communis Linn. and their antibacterial activity. Int J Res Pharm Chem. 4:611-618, 2014.

[18] CLSI - Clinical and Laboratory Standards Institute. Reference method for broth dilution antifungal susceptibility testing of yeast; approved standard-third edition. CLSI document M27-A3. Wayne, PA: Clinical Laboratory Standards Institute, 2008.

[19] Alibrandi P, Cardinale M, Rahman MM, Strati F, Cina P, de Viana ML et al. The seed endosphere of Anadenanthera colubrina is inhabited by a complex microbiota, including Methylobacterium spp. and Staphylococcus spp. with potential plant-growth promoting activities. Plant Soil. 422:81-99, 2018.

[20] Rodríguez RJ, Redman RS, Henson JM. The role of fungal simbiosis in the adaptation of plants to high stress environments. Mitig Adap Strat Glob Change. 2004; 9:261-272.

[21] Arnold AE, Henk DA, Eells RL, Lutzoni F. "Diversity and phylogenetic affinities of foliar fungal endophytes in loblolly pine inferred by culturing and environmental PCR". Mycologia. 99:185206, 2007.

[22] Van Bael SA, Maynard Z, Robbins N, Bischoff J. "Emerging Perspectives on the Ecological Roles of Endophytic Fungi in Tropical Plants. In: The Fungal Community: Its Organization and Role in the Ecosystem (White JF Jr, Dighton J, Oudemans P, eds.)". MarcelDekker. New York, USA, 181-191, 2005.

[23] Porras-Alfaro A, Bayman P. Hidden fungi, emergent properties endophytes and microbiomes. Annu Rev Phytopathol. 49:291-315, 2011.

[24] Mini PR. Endophytic actinomycetes from Indian medicinal plants as antagonists to some phytopathogenic fungi. Scient Rep. 1:259, 2012. https://doi:10.4172/scientificreports.259.

[25] Mahendra R, Gauravi A. "Plant-fungal interactions: What triggers the fungi to switch among lifestyles?". Crit Rev Microbiol. 42:428-438, 2013.

[26] Sun X, Ding Q, Hyde HD, Guo LD. "Community structure and preference of endophytic fungi of three woody plants in a mixed forest". Fungal Ecol. 2012 https://doi:10.1016/j.funeco.2012.04.001.

[27] Toghueo RMK, Zabalgogeazcoa I, Vázquez de Aldana BR, Boyom FF. Enzymatic activity of endophytic fungi from the medicinal plants Terminalia catappa, Terminalia mantaly and Cananga odorata. South African J Bot. 109:146-153, 2017.

[28] Schulz B, Guske S, Dammann U, Boyle C. "Endophyte-host interactions II. Defining symbiosis of the endophyte-host interaction". Symbiosis. 25: 213-227, 1998.

[29] Schulz B, Boyle C. The endophytic continuum. Mycol Res. 109:661686, 2005.

[30] Guo B, Wang Y, Sun X, Tang K. Bioactive natural products from endophytes: A review. Appl Biochem Microbiol. 44:136-144, 2008.

[31] Verma VC, Kharwar RN, Strobel GA. Chemical and functional diversity of natural products from plant associated endophytic fungi. Nat Prod Commun. 4:1511-1532, 2009.

[32] Li JY, Harper JK, Grant DM, Tombe BO, Bashyal B, Hess WM, et al Ambuic acid, a highly functionalized cyclohexenone with antifungal activity from Pestalotiopsis spp and Monochaetia spp. Phytochemistry. 56:463-468, 2001

[33] Krohn K, Biele C, Drogies KH, Steingrover K, Aust HJ, Draeger S, Schulz B. Fusidilactones, a new group of polycyclic lactones from an endophyte, Fusidium sp. Eur. J Org Chem. 14:2331-2336, 2002.

[34] Li JY, Strobel GA, Harper JK, Lobkovsky E, Clardy J. Cryptocin, a potent tetramic acid antimycotic from the endophytic fungus Cryptosporiopsis cf. quercina. Org Lett. 2:767-770, 2000. 